\title{
ESTIMATIVAS DE CORRELAÇÕES FENOTÍPICAS, GENOTÍPICAS E DE AMBIENTE ENTRE SETE CARACTERES MORFOAGRONÔMICOS EM OITO ACESSOS DE MORANGA $\left(^{1}\right)$
}

\author{
ANTONIO T. AMARAL JÚNIOR $\left({ }^{2}\right)$, VICENTE WAGNER D. CASALI $\left({ }^{2}\right)$, \\ COSME DAMIÃO CRUZ $\left({ }^{3}\right)$, DERLY JOSÉ H. DA SILVA $\left({ }^{2}\right)$ e LUIZ F. CORBEIRA DA SILVA $\left({ }^{2}\right)$
}

\begin{abstract}
RESUMO
Sete caracteres morfoagronômicos, avaliados em oito acessos de moranga ( $C u c u r-$ bita maxima Duchesne) foram submetidos à análise de correlaçōes fenotípicas, genotípicas e de ambiente. As correlações genotípicas foram superiores às fenotípicas e de ambiente, indicando moderada influência deste último na expressão dos caracteres. Todos os pares de caracteres apresentaram correlações genotípicas positivas $(>0,75)$, evidenciando que a seleção para aumento na média de um caráter provocará alteraçōes na média do outro, no mesmo sentido. Os caracteres comprimento da rama principal até a primeira flor feminina (RAMA F) e o comprimento da rama principal até o ápice (RAMA T) apresentaram a maior correlação genotípica, enquanto a menor magnitude dessa correlação ocorreu entre o número de nós da rama principal até a primeira flor feminina (NS F) e o comprimento médio do internódio da rama principal até o ápice (COMP $\mathrm{T}$ ).
\end{abstract}

Termos de indexação: moranga, Cucurbita maxima Duchesne, correlações.

\begin{abstract}
ESTIMATES OF PHENOTYPIC, GENOTYPIC AND ENVIRONMENT CORRELATIONS AMONG SEVEN MORPHOLOGICAL AND AGRICULTURAL TRAITS IN EIGHT PUMPKIN ACCESS
\end{abstract}

Seven morphological and agricultural traits were analysed in eight access of pumpkin (Cucurbita maxima Duchesnc). They were subjected to a phenotypic, genotypic and environment correlations analysis. The genotypic estimates showed botter correlation results than the phenotypic and environmental estimates. Also indicated a moderated influence by the environment in the trait expression. All pairs of traits

(1) Recebido para publicação em 25 de novembro de 1993 e aceito em 5 de setembro de 1994.

(2) Departamento de Fitotecnia, Universidade Federal de Viçosa, 36570-000 Viçosa (MG).

(3) Departamento de Biologia Geral, Universidade Federal de Viçosa, 36570-000 Viçosa (MG). 
showed positive genotypic correlation $(>0.75)$ with evidences that the selection aims the increase of traits average, and also it leads to an alteration in the average of the other traits in the same amount. The RAMA F traits (the lenght of the stem until the first female flower) and RAMA T (the lenght of the stem until the top) showed the highest genotypic correlation, while the minor magnitude in this correlation occurred between NS F (number of nodes in the stem until the first female flower) and COMP T (the median lenght of stem's internodes until the top).

Index terms: pumpkin, Cucurbita maxima Duchesne, correlations.

\section{INTRODUÇÃO}

Correlação é uma medida do grau com que duas variáveis variam juntas ou da intensidade de associação entre essas variáveis (Steel \& Torrie, 1960; Kempthorne, 1973; Gopalakrishman et al., 1980).

Tal associação adquire importante conseqüência para o melhorista, pois permite a seleção indireta do caráter desejado, principalmente quando os caracteres envolvidos possuem herança complexa e estão correlacionados com um caráter facilmente identificável à seleção (Robinson et al., 1951). De acordo com Falconer (1987), o conhecimento da associação entre caracteres agronômicos e morfológicos e as conseqüências causadas pela mudança simultânea de dois caracteres quaisquer podem resultar em maior eficiência na seleção dos caracteres a serem melhorados, bem como em ganho de tempo e economia de trabalho, do que a seleção isolada para determinado caráter.

Falconer (1987) afirma que a correlação fenotípica tem pouco valor prático, podendo seu uso ocasionar erros. Assim, é importante, no estudo de correlações, distinguir as causas genética e de ambiente que, combinadas, resultam na correlação fenotípica (Mather, 1965; Falconer, 1987; Almeida, 1988).

O presente trabalho foi elaborado com o objetivo de estimar as correlações fenotípicas, genotípicas e de ambiente entre sete caracteres morfoagronômicos avaliados em oito acessos de moranga, do Banco de Germoplasma de Hortaliças (BGH) da Universidade Federal de Viçosa.

\section{MATERIAL E MÉTODOS}

Foram utilizados oito acessos de moranga, do Banco de Germoplasma de Hortaliças (BGH) da Universidade Federal de Viçosa (Quadro 1). Os genótipos, constituídos por populações de polinização aberta, foram cultivados na Horta do Departamento de Fitotecnia da Universidade Federal de Viçosa, seguindo-se os tratos culturais normalmente empregados para a cultura, plantados no delineamento em blocos casualizados, com oito acessos e quatro repetições, sendo as parcelas constituídas por três covas com duas plantas cada uma.

Os seguintes caracteres foram avaliados:

a) ANTESE: número de dias da semeadura à antese da primeira flor feminina;

b) RAMA F: comprimento da rama principal até a primeira flor feminina;

Quadro 1. Acessos de moranga com as respectivas identificações e procedências

Acessos

Procedência

BGH 1908

BGH 4520

BGH 5458

BGH 5615

BGH 5618

BGH 5628

BGH 5642

BGH 6158
Aimorés, MG

EMBRAPA - Brasília, DF

ESALQ - Piracicaba, SP

EMBRAPA - Brasília, DF

Ceará, CE

Ceará, CE

EMBRAPA, Brasília, DF

EMPASC, SC 
c) RAMA T: comprimento da rama principal até o ápice;

d) NS F: número de nós da rama principal até a primeira flor feminina;

e) NS T: número de nós da rama principal até o ápice;

f) COMP F: comprimento médio do internódio da rama principal até a primeira flor feminina;

g) COMP T: comprimento médio do internódio da rama principal até o ápice.

A análise estatística, fundamentada nas médias das parcelas, foi processada pelos recursos computacionais do Programa GENES, desenvolvido pelo
Setor de Genética do Departamento de Biologia Geral da Universidade Federal de Viçosa.

\section{RESULTADOS E DISCUSSÃO}

No quadro 2 são apresentadas as estimativas dos coeficientes de correlações fenotípicas ( $\mathrm{rF}$ ), genotípicas $\left(\mathrm{r}_{\mathrm{G}}\right)$ e de ambiente $\left(\mathrm{r}_{\mathrm{A}}\right)$ entre os caracteres avaliados.

As correlações genotípicas foram superiores às fenotípicas e de ambiente, indicando moderada influência do ambiente na expressão dos caracteres. Resultados análogos foram encontrados, em moranga, por Almeida (1988) e Moura (1989).

Quadro 2. Estimativas dos coeficientes de correlação fenotípica ( $\mathrm{r}_{\mathrm{F}}$ ), genotípicas (rG) e de ambiente ( $\mathrm{r}_{\mathrm{A}}$ ) entre sete caracteres morfoagronômicos $\left(^{1}\right)$

\begin{tabular}{lcrr}
\hline \multicolumn{1}{c}{ Correlações } & rF & $\mathrm{r}_{\mathrm{G}}$ & $\mathrm{r}_{\mathrm{A}}$ \\
\hline ANTESE x RAMA F & 0,9003 & 0,9253 & 0,0384 \\
ANTESE x RAMA T & 0,8712 & 0,9023 & $-0,4225$ \\
ANTESE x NS F & 0,8606 & 0,8879 & 0,3372 \\
ANTESE x NS T & 0,8931 & 0,9179 & 0,2048 \\
ANTESE x COMP F & 0,8703 & 0,9027 & $-0,3051$ \\
RAMA F x RAMA T & 0,9902 & 0,9921 & 0,4996 \\
RAMA F x NS F & 0,9526 & 0,9689 & 0,6699 \\
RAMA F x NS T & 0,9596 & 0,9649 & 0,5281 \\
RAMA F x COMP F & 0,9499 & 0,9549 & 0,0723 \\
RAMA F x COMP T & 0,8853 & 0,8934 & $-0,0145$ \\
RAMA T x NS F & 0,9209 & 0,9415 & 0,2996 \\
RAMA T X NS T & 0,9418 & 0,9480 & 0,3995 \\
RAMA T x COMP F & 0,9663 & 0,9707 & 0,2201 \\
RAMA T X COMP T & 0,9295 & 0,9334 & 0,5962 \\
NS F x NS T & 0,9805 & 0,9897 & 0,8182 \\
NS F x COMP F & 0,8134 & 0,8487 & $-0,6094$ \\
NS F x COMP T & 0,7184 & 0,7527 & $-0,4129$ \\
NS T x COMP F & 0,8556 & 0,8699 & $-0,4008$ \\
NS T x COMP T & 0,7572 & 0,7756 & $-0,4580$ \\
COMP F x COMP T & 0,9696 & 0,9740 & 0,5998 \\
\hline
\end{tabular}

( ${ }^{1}$ ) ANTESE = número de dias da semeadura à antese da primeira flor feminina; RAMA F = comprimento da rama principal até a primeira flor feminina; RAMA $\mathrm{T}=$ comprimento da rama principal até o ápice; NS $\mathrm{F}=$ número de nós da rama principal até a primeira flor feminina; NS $\mathrm{T}=$ número de nós da rama principal até o ápice; COMP $\mathrm{F}=$ comprimento médio do internódio da rama principal até a primeira flor feminina; COMP $\mathrm{T}=$ comprimento médio do internódio da rama principal até o ápice. 
Segundo Falconer (1987), as diferenças de sinais entre correlações genotípicas e de ambiente indicam que as causas de variação genética e de ambiente influenciaram os caracteres por mecanismos fisiológicos diferentes. Esse fato pode ser constatado neste trabalho em relação às correlações entre antese e: RAMA T, COMP F e COMP T; entre RAMA $F$ e COMP T; entre NS F e: COMP F e COMP T; e entre NS T e: COMP F e COMP T. Utilizando-se a última correlação como exemplo, pode-se afirmar que as plantas com maiores valores de COMP $F$ e COMP T tenderão também a apresentar maiores valores de NS T; entretanto, o ambiente que favorece um incremento nos valores de NS T desfavorece os caracteres COMP F e COMP $\mathrm{T}$.

Em todas as combinações entre caracteres estudados, as correlações genéticas foram positivas $(>0,75)$, indicando que a seleção visando a incremento de um caráter provocará alterações no outro, no mesmo sentido. A maior magnitude de correlação genotípica $(0,9921)$ ocorreu entre os caracteres RAMA F e RAMA T. Por outro lado, os caracteres NS F e COMP T apresentaram a menor correlação genotípica $(0,7527)$.

O caráter ANTESE correlacionou-se genotipicamente de forma positiva com a maior magnitude ao caráter RAMA F, indicando que plantas mais precoces tenderão a apresentar menores comprimentos de rama, caracterizando genótipos de porte arbustivo. Entretanto, as correlações de ambiente entre os caracteres ANTESE e RAMA T foram negativas, mostrando que não foram influenciados pelas mesmas variações nas condições de ambiente.

Analogamente, constata-se que o ambiente, ao atuar em sentidos opostos para com ANTESE e: COMP F e COMP $T$, favoreceu a precocidade, em detrimento dos comprimentos médios de internódios, o que é aceitável, uma vez que antese se correlacionou positivamente com NS F e NS $\mathrm{T}$, os quais se correlacionaram negativamente com COMP F e COMP $\mathrm{T}$, mostrando que o ambiente, ao favorecer a correlação precocidade e menor número de nós, interferiu contrariamente com a correlação precocidade e comprimento médio do internódio.

\section{CONCLUSÕES}

1. As correlações genéticas foram positivas $(>0,75)$ e superiores às fenotípicas e de ambiente.

2. A maior magnitude de correlação genotípica ocorreu entre os caracteres RAMA F e RAMA T, enquanto, entre NS F e COMP $T$, evidenciou-se a menor correlação genotípica.

3. Em alguns pares de caracteres, as correlações de ambiente foram negativas e as genotípicas, positivas, mostrando que não foram influenciadas pelas mesmas variações nas condições de ambiente.

\section{REFERÊNCIAS BIBLIOGRÁFICAS}

ALMEIDA, A.H.B. Heterose e correlações em plantas braquíticas e normais de jerimum caboclo (Cucurbita maxima Duchesne). Viçosa, 1988. 63p. Dissertação (Mestrado em Genética e Melhoramento) - UFV, 1988.

FALCONER, D.S. Introdução à genética quantitativa. Trad. SILVA, M.A. \& SILVA, J.C. Viçosa, UFV. Imprensa Universitária, 1987. 279p.

GOPALAKRISHMAN, T.R.; GOPALAKRISHMAN, P.K. \& PETER, K.V. Variability, heritability and correlation among some polygenic characters in pumpkin. Indian Journal of Agricultural Sciences, New Delhi, 50(12):925-930, 1980

KEMPTHORNE, O. An introduction to genetic statistics. Ames, Iowa, State University Press, 1973. 454p.

MATHER, W.B. Principles of quantitative genetics. Burgess Publishing Company, 1965. 152p.

MOURA, V.M. Avaliação de progênies $F 2$ derivadas de introduções braquitica e normais de moranga (Cucurbita maxima Duchesne). Viçosa, 1989. 74p. Dissertação (Mestrado em Genética e Melhoramento) - UFV, 1989.

ROBINSON, H.F; COMSTOCK, R.E. \& HARVEY, P.H. Genotypic and phenotypic correlations in corn and their implications in selection. Agronomy Journal, Madison, 43:282-287, 1951.

STEEL, R.G.D. \& TORRIE, J.H. Principles and procedures of statistics. New York, McGraw Hill, 1960. $481 \mathrm{p}$. 